\title{
Web-based psychosocial interventions for survivors of child sex tourism and their families: a rethink of counselling
}

\author{
Yahya Muhammed Bah ${ }^{1}$, Myrtati Dyah Artaria ${ }^{1 *}$, Mein-Woei Suen ${ }^{2}$ \\ ${ }^{1}$ University of Airlangga, Surabaya, Indonesia \\ ${ }^{2}$ Department of Psychology, Asia University, Taichung, Taiwan \\ *Corresponding author, e-mail: myrtati.artaria@fisip.unair.ac.id
}

\begin{abstract}
Daily, in almost every part of the world, series of maltreatment are meted on the children. Because of their vulnerability, the time has come to take serious actions and unreserved measures to end this inhumane treatment and support the victims and their communities. Children are innocent beings and are the last hope of every community and nation and deserve a decent and safe environment to grow to the fullest. This is a fundamental human right as capsulated in the United Nations Convention on the Rights of the Child (UNCRC), an international legal instrument of universal significance. A systematic review of the works of literature using information collected from different sources was actuated. Google search engine, google scholar, web of science, and Scopus database were used to search for these articles. During the search, combinations of words and phrases were used to ensure articles reflected the most current knowledge and scholarly works. The systematic searches beget varied and voluminous articles that had to be sieved not only to meet the inclusion and exclusion criteria but also to ensure the fundamental objectives of the study are wrangled. In summary, the potentials of web-counseling include but are not restricted to unlimited access and improved seeking behavior, affordability, convenience, limited pressure, permanent record availability, anonymity, independence and autonomy, empowerment, geographical barriers elimination, less feeling shy, freedom of expression, confidentiality, and privacy, efficiency and effectiveness improvement, alltime access to multiple therapists, resources with no transport cost and hassle, and client-driven therapy sessions
\end{abstract}

Keywords: child sex tourism, e-counselling, e-therapy, web-interventions, and psychosocial support

How to Cite: Bah, Y. M., Artaria, M. D. \& Suen, M. (2021). Web-based psychosocial interventions for survivors of child sex tourism and their families: a rethink of counseling. International Journal of Research in Counseling and Education, 5 (1): pp. 39-55, DOI: https://doi.org/10.24036/00430za0002

This is an open access article distributed under the Creative Commons 4.0 Attribution License, which permits unrestricted use, distribution, and reproduction in any medium, provided the original work is properly cited. @2021 by author.

\section{Introduction}

In general terms to effectively protect children and provide support services for survivors of abuse, it calls for the participation of all particularly specialized institutions (Goldman et al., 2003). Thus, to deliver any support services to victims of sexual abuse, there is an urgent need for collaboration between institutions (Goldman et al., 2003). The support services needed by sexually abused children can be widely classified into medical, psychosocial, judicial services; and social services (Muridzo et al., 2018). Thus, it demands the participation of several professionals including social workers, doctors, nurses, police officers, magistrates, prosecutors, counsellors; and psychologists (Muridzo et al., 2018). In this regards, the establishment of multidisciplinary team of professionals including social workers, health workers, counsellors, psychologists, police, lawyers, etc. housed under one roof especially in a university teaching hospital would be ideal (Chomba et al., 2010).

In view of the above assertions, counselling is fundamental in the remobilization of the victims and families energy for successful recovery and reintegration. To expedite recovery and reintegration of survivors and further support their families particularly the parents, counselling and the provision of impartial professional advice is indispensable (Whittle et al., 2013). To assist child-victims recover and reintegrate, it is fundamental social workers and counsellors don't work with non-offending parents only but equally offer the entire family the needed psychosocial support through counselling as its status has direct bearing on the wellbeing of the 
victims (Grant, 2006). In reducing the negative impacts of sexual abuse, survivors need counselling services that can accord them safe and secured environment, encouragement, opportunities for empowerment, skills to build and maintain long-term supportive relationship and furthermore be able to address more general psychosocial problems being encountered before the abuse (Hall \& Hall, 2011).

In light of the voluminous demand for counselling services due to numerous pandemics, there is urgent need for robot ways of solving this need particularly for child survivors of sexual abuse and their families. Thus, counselling services delivery methods like other services need to be innovative. Information Communication Technologies (ICTs) have commenced to render such opportunities even in the delivery of counselling via webbased psychosocial interventions in the name of online counselling. Online counselling is interchangeable with cyber counselling, internet therapy, e-counselling, e-therapy, e-mail therapy, internet counselling and webcounselling (Paterson et al., 2019).

\section{Methodology}

A systematic review of the literatures using information collected from different sources was actuated. Google search engine, google scholar, web of science; and scopus database were used to search for these articles. During the search numeration combinations of words and phrases were used to ensure articles reflect the most recent knowledge and scholarly works. The systematic searches beget varied and voluminous articles which had to be sieved not only to meet the inclusion and exclusion criteria but to ensure the fundamental objectives of the study are wrangled.

Therefore, only peer-reviewed scholarly publications published after 2000 were selected except extracts perceived to be of basal mileage to the study. However, articles published by staunch international organizations known to have been working in child rights and child protection and provision of psychosocial support for years and has produced indefatigable knowledge were stealthily appraised.

\section{Inclusion and Exclusion Procedures}

The underneath procedures were followed in articles inclusion. That is, only:

1. Peer-reviewed scholarly articles on web-based psychosocial interventions needed by survivors of psychosocial problems including child sexual abuse.

2. Peer-reviewed scholarly articles published from 2000 to 2021.

3. Articles on international or regional perspectives web-based psychosocial interventions for survivors of psychosocial problems including child sexual abuse.

4. Articles on psychosocial support services needed by survivors of child sexual abuse published by international organizations with years of meritorious experiences in child rights and child protection.

To exclude some articles from the review, the below captioned criteria were applied. That is:

1. Non-peer reviewed articles.

2. Articles published before 2000 unless critical and impactful.

3. Media generated articles including newspapers.

4. Articles not published in English language.

In spite of the fact that both qualitative and quantitative articles were trawled, only 96(ninety six) articles were qualified for review which is largely due to a dearth of data. In essence, only peer-reviewed articles and publications by international organizations considered being trustworthy because they occasioned standard, ethical and robust studies were reviewed.

\section{Discussions}

The literature review has unearthed a wide range of opportunities and challenges in web-based psychosocial interventions. To discuss these, they are categorized into: unlimited access and improved seeking behavior, affordability, convenience, limited pressure, permanent record availability, anonymity, independence and autonomy, empowerment, geographical barriers elimination, less feeling shy, freedom of expression, confidentiality and privacy, efficiency and effectiveness improvement, all time access to multiple therapists, resources with no transport cost and hassle, and client-driven therapy sessions.

The challenges, loss of human factor and complete virtual relationship, internet connectivity, less nonverbal and verbal cues, misinterpretation and misunderstanding, limited access to computers and computing skills, technological complication and failures, security and confidentiality, composing concise and simple messages, therapists' competence verification, culture and time differences, client identification, delay in rapid and emergency support delivery, impersonation and giving false information, and staff re-training, hiring of new ones and purchasing new equipment. 


\section{Unlimited access and improved seeking behavior}

A good number of the people in difficult circumstances including sexually abused persons would like to seek support either through the formal or informal structures based on the person and his or her environment. However, there are many factors that deterred people from asking for help which can be either psychosocial, environmental in nature, economical or even the proximity of the service providers and their attitudes (Kantor et al., 2017). Traumatized and sick people would most of the time like to seek support if the services are accessible, affordable and delivered with respect, concurring with in a pandemic like Covid-19, the adoption of telepsychotherapy is very critical both to cope with demand and ensure accessibility at reasonable cost and time (Boldrini et al., 2020). The act of writing is not a mean of conveying messages and feelings only but in ecounselling a form of therapy to both prevent more deterioration and speedy recovery for some clients (Wright, 2002). Online counselling is cost effective because its allows clients access to greater and less stigmatized service delivery choice while expediting availability and delivery as resources are limited and cannot be overstretch in support of face-to-face counselling (Wright, 2002). Online counselling is beneficial to the seriously disadvantaged group especially those with disabilities, terminally ill, senior citizens, the elderly, those who cannot leave their homes; and most importantly it can reach anyone anywhere in the world (Chester \& Glass, 2006). Online counselling in addition to resulting in significant increase in the quality of life and fewer alcohol consumption, it has created a good avenue for the younger generation and higher risk clienteles to easily access counsellors for support (Frings et al., 2020).

Similarly, in view of the fact that many people cannot easily access mental health services in Japan, many people including students are switching to online counselling services (Li \& Leung, 2020). Web therapy is beneficial for many reasons such as enhancing group support and networking, virtual reality application, quick assessment and monitoring, the use of emails and blogs that are seemingly unavailable or non-applicable in the traditional face-to-face counselling sessions (Barak et al., 2009). Online counselling is beneficial because it can be delivered via different media: telephone, asynchronous email, text or messages posted in a chat room and so froth boosting its accessibility (Paterson et al., 2019). Online counselling is gaining wider recognition as the internet is becoming a major and formal source for accessing series of services including counselling particularly for the adolescents (Chardon et al., 2011). With accessible and affordable technology the adoption of internet for the delivery of psychological support has increased and furthermore its regular application in most part of the globe boosted (Perle et al., 2011). E-therapy is beneficial because it increases the rate at which non-treatment seeking population are opting to seek treatment while minimizing the number of attrition (Gainsbury \& Blaszczynski, 2011).

\section{Affordability}

Cost is a great determinant factor in people looking for a service and willingness to pay for it especially for the economically deprived communities (Muller \& Ruffieux, 2011). Therefore, any price that makes a service affordable can be a great influencer for people to chase such a service including psychosocial support particularly if it is a perfect or near perfect substitute of the traditional one as support by with effective online counselling implementation in the healthcare and social welfare services delivery structures, it will enhance access to more services at reasonable cost, rapid delivery of professionals' feedback on problems, increase in knowledge and impacts in any given problem, and the reduction or cessation of existing social problems (Tomazic \& Jerkovic, 2020). Web-counselling is significant in many regards such as the application of modern technology to address psychosocial problems, to conduct rapid assessments, evaluations, accessing disenfranchised clients and most importantly delivering affordable and efficient therapy in very remote locations (Mallen, Vogel, \& Rochlen, 2005). E-counselling which generally include the provision of advice and support to counselees via textual communication that is shared back and forth between therapist and clienteles in real time is revolutionizing and making affordable psychosocial treatment required by clienteles (Abbott et al., 2008).

Similarly, e-therapy is advantageous for many reasons namely availability, convenience, accessibility, costeffectiveness, anonymity, and privacy as cited in Monaghan et al. 2009a\&b (Gainsbury \& Blaszczynski, 2011). In view of the fact that some clienteles only need someone who can listen to them non-judgmentally, webcounselling is good in reducing the impacts of social isolation and at the same time for rendering little, widely affordable and quick support (Wilson et al., 2017). However, (Dilkes-Frayne et al., 2019) observed differently: though in some instances, online counselling is more accessible than traditional face-to-face, it is somehow becoming unaffordable because of how the services are organized and funded.

\section{Convenience}

The ability to use a service with comfort is critical in the way people want to be associated with it and furthermore even pay for it. In essence, to make access and usability of a service and even a product sophisticated can discourage many people from opting for it especially the sick, illiterates and highly occupied ones (van Kuijk et al., 2015). Thus, most service seekers including those looking for psychosocial interventions would prefer user-friendly ones not only to save their time but avoid being traumatized once more concurring 
with because of the massive revolution ushered in through technology, it is highly recommended that all institutions switch immediately to e-counselling to cope with the unprecedented psychosocial problems with comfort and at moderate cost (Supriyanto et al., 2020). Due to the perceived usefulness, convenience and relevance of online counselling in the modern world, a significant proportion of psychologists are opting for it in support of their clientele based (Lazuras \& Dokou, 2016). Web-counselling is fundamental and convenient in providing avenue for the creation of the first contact needed by a client and the counsellor in delivering brief intervention that a client would need before being referred to appropriate professionals for more interventions (Wilson et al., 2017). In general terms, psychologists around the globe are shifting their attitudes and attention toward tele-health particularly e-therapy especially for those who have been working in the army and prison systems because of convenience and efficiency (Perle et al., 2011).

Similarly, in comparison with face-to-face counselling, clienteles find it easier to look for support through web based intervention since there is no need for a direct personal contact with the counsellors (Gainsbury \& Blaszczynski, 2011). In general terms e-therapy is beneficial in challenging and treating with more convenience a range of behavioral difficulties being due to abuse of substance or non-substantial (Gainsbury \& Blaszczynski, 2011).

\section{Limited pressure}

Generally, most service seekers don't want to be put under pressure for with pressure, they are either completely dissatisfied with the service at the end of the day or they prematurely withdraw (Spake et al., 2003). Though some social welfare services are not being paid for or clienteles are moderately charged, they need to be treated with respect including not being put at rush (Ellis et al., 2018). Moderately flexible and humanly working relationship is not only a fundamental human right of clients but as well it is therapeutic in nature as they can seek support at any time while feeling welcome as encapsulated in web-counselling is beneficial in many respects as it can permit consultation outside working hours for busy people, for those who preferred seeking support through text messages, those who want to discuss child protection matters; and for those who don't want to look for support in-person because of stigma, safety concerns (Dilkes-Frayne et al., 2019).

\section{Permanent record availability}

In any transaction, keeping accurate and accessible records is very important. With records, what has transpired between two or more parties can be easily noted for necessary action, learning and further improvement of services (Shonhe, 2018). In social work, because of the significant of recording and keeping records, it is strongly believed that apart from it being an integral part of social work, what is not recorded including services offered is not done (NLASW, 2014) \& (SCIE, 2019). Recording and keeping records because it is tedious and time consuming, any application or software, that can perform it with accuracy can be very critical in service delivery including counselling as authenticated: e-therapy is easier to monitor and evaluate treatment progress since all the needed data are recorded electronically and transcribed for both researchers and clienteles to access effortlessly (Gainsbury \& Blaszczynski, 2011).

\section{Anonymity}

Some people very much like to remain anonymous or non-identifiable in some of their engagements no matter how genuine or beneficiary it can be to the wider community for reasons best known to them. However, in some situations people want to be non-identifiable because of fear of stigma and social isolation just because of the opinion they hold, spiritual belief, associations or sickness (Judd \& Vandenberg, 2014) and (Parcesepe \& Cabassa, 2012). In some parts of the globe, persons seeking support from social welfare institutions are highly stigmatized either because they are seen as failures or are encountering huge problems with their health or family (Spicker, 2011). Thus, since with web-based psychosocial interventions, a person can sit anywhere and login in the internet and seek for the support of counsellors without anyone noticing, it has encouraged lot of people to come forward and look for support and even discuss sensitive issues which they would not have done concurring with online counselling in addition to being beneficial to persons with disabilities, first time helpseekers, those in the rural and remote areas, in comparison with traditional face-to-face counselling; it is more effective, convenient, affordable, eliminate the social stigma in seeking and receiving therapy furthermore, it enhances anonymity, self-disclosure and honesty in clienteles explaining their concerns (Muraina et al., 2020). Web-therapy is ideal for clienteles for easy access, privacy, anonymity, it is a pathway to access different therapies and services, and it boosts the help-seeking attitudes of families and their members (Rodda et al., 2013). Online counselling is favored by increasing number of health service seekers for many reasons such as anonymity, efficacy, safer and less emotional exposure (Chardon et al., 2011).

\section{Independence and autonomy}

Being fully in control of one's affairs and destiny is critical in the psychosocial and economic development of any one and by extension of any community (Serdiuk et al., 2018). With full autonomy people are not only on high gear, they can choose what they want to do, what they want to be and how they want things to be done as they are experts in their own right. However, this doesn't mean people don't need to be supported to 
complement their efforts but rather they don't want to live or work under dictatorship or imposition of any kind. Being in control of one's affairs is mentally and physically relaxing for it allows one to think deeply and willingly mobilize all the required energy not only to failed but recover if in difficult circumstances while empowering oneself (UNDESA, n.d.), concurring with e-therapy is motivating because it enhances the building of the therapeutic relationship, autonomy of clienteles in the sense that they are somehow in control of the sessions, processes, avoid face-to-face support, allows additional time for thinking, in most cases, it is a therapy tool box, reduces isolation and psychosocial pressure, increases the value of therapeutic writing as everything is written, anonymity and client concealment; and increases the needed social support since the platform is some sort of a community (Hanley \& Wyatt, 2020). Students preferred e-counselling for many reasons such as it facilitates the building of therapeutic relationship, increases independence and autonomy during work; and reduces the anxiety in face-to-face counselling (Hanley \& Wyatt, 2020).

\section{Empowerment}

At any stage of development, being able to do things by oneself without asking for support is cardinal and rewarding in all aspects of life and living (Collier \& Wayment, 2018). Thus, majority of the people would like to be empowered even those in difficult circumstances as they would under normal situation prefer support that empowers them than those that enslaved them. In view of the ultimate objective of psychosocial interventions is to rehabilitate and restore loss or diminished abilities, clienteles would opt for less complex and empowering therapies concurring with web-interventions among other things have the power to track clienteles' behaviors, sleeping patterns, level of changes in activities, empowerment, etc. across different types of clienteles with mood disorder (Alavi et al., 2020). Technology based counselling via WhatsApp, Facebook, Instagram or Social media, Zoom, Webex, Google Meeting, or Hangout were named as the best and most appropriate alternatives to solve students' problems and furthermore developed their potentials (Supriyanto et al., 2020). Web-therapy has significantly empowered families and their members to be able to adequately handle their psychosocial problems including gambling (Rodda et al., 2013). Web-counselling has among other things improved families ability and readiness to make first contact with professionals, relieving distress, planning appropriate action, communication, regaining direction, and connection with available local services (Dilkes-Frayne et al., 2019).

\section{Geographical barriers elimination}

To a very large extent, people's development and success in life is influenced by their geographical location on the globe (Maté-Sánchez-Val et al., 2018). In some part of the globe people's movement both at national and international level are reasonably cheap and easy availing them the chances to grab and utilize opportunities for growth and success. However, others because of geographical barriers, their development and success in life is largely handicapped (Cresswell \& Underwood, 2004). Therefore, any innovation that can break these barriers will be more appreciated and embraced even in the social and health service industry as some associated costs are knocked off concurring with psychotherapists are motivated to apply webcounselling due to many factors such as the existing psychotherapy models, clinical experiences, previous experiences with online interventions, unavoidable transition due to the Covid-19 pandemic and their geographical location (Békés \& Doorn, 2020). E-counselling is beneficial to the less privileged groups particularly persons with disabilities who find accessing face-to-face counselling difficult either because of the distance or because they are deaf and hard of hearing depending solely on interpreters (Wright, 2002). In view of the current knowledge, online counselling is beneficial to many clienteles especially those who are victims of social isolation and those far from counselling facilities (Mallen, Vogel, Rochlen, et al., 2005). While more research is needed in how online counselling services can improve the general wellbeing of clienteles and their relatives, it has significantly broken the barriers deterring access to support services for relatives' on alcohol and other drug abuse (Dilkes-Frayne et al., 2019).

For the same token, the application of tele-health in the delivery of much needed health services is unprecedentedly widening, breaking geographical barriers and all opportunities presented must be grabbed without delay (Perle et al., 2011). E-therapy offers huge degree of access since it breaks those barriers due to geographical location, time, pride, fear of stigma, and pressure from counsellors (Gainsbury \& Blaszczynski, 2011). Cyber counselling is advantageous for its accessibility, flexibility, overcoming of distance problems making it accessible to a wider clienteles regardless of geographical location; and eases clienteles accessing materials at any time (Chester \& Glass, 2006).

\section{Less feeling shy}

For some people feeling shy is part of their human nature (BBC, 2021). However, it must be a reasonable one otherwise it can be detrimental to oneself and others. For some people, they are so shy, they can hardly express their immediate needs no matter how much burning and urgent they are. Therefore, with such kind of behaviors, it can be rightly assumed that such clienteles will in the first place find it extremely difficult to approach a therapist much more to reveal issues that are confidential. This is worse if they are highly controversial to held fundamental societal values and norms. Sometimes, it can be destructive depending on the degree (Afshan, 2015). Thus, with any mean of establishing contact with therapists without having to face 
him or her physically, it will significantly motivate such kind of clienteles to come out and seek interventions with eagerness as corroborated: generally, web-counselling is beneficiary to clients who have very busy schedule and those who you feel too shy to seek support because of the social stigma associated with seeking and receiving it and those located in areas that are far from counselling centres (Frye-cox et al., 2020). Webbased interventions are found to be effective in achieving the needed positive behavioral change by reducing some basic behavioral problems and furthermore, it is useful in addressing untreated problems and importantly breaking barriers for help-seekers to look for help without shame or delay (Chebli et al., 2016).

Similarly, web-based intervention has become so popular and trusted by the young persons they now do not feel ashamed to discuss sensitive issues such as mental health that are impacting their lives which they would not have talk about with counselor in traditional face-to-face counselling sessions (Li \& Leung, 2020). Etherapy reduces the degree of feeling shame, guilt, lack of willingness to disclose disorder, missing assessment appointment and dropping out of a chosen treatment plan in addition to easy access and the wide range of services on offer (Gainsbury \& Blaszczynski, 2011).

\section{Freedom of expression}

Freedom of expression is no longer a privilege but a fundamental human right that should be enjoyed by all regardless of socio-economic and political standing in the community (Nations, n.d.). Without the freedom for people to express themselves, they are enslaved. Enslaved people hardly have any saying even over their own wellbeing. Therefore, any mechanism that liberate them from such bondage, will not only empower them, put their destiny in their own hands, permit them to demand their other rights but protest against the violation of any right (McLeod, 2018). Thus, any modality of intervention that accords people such rights will be highly appreciated and utilize to the maximum for the rapid attainment of sough support as support by web-therapy is effective in reducing depression, eliminate social stigma, allows clienteles to retain anonymity, increases freedom of expression, permits easy recording and saving of records together with reference materials to reread, rehearse, etc. to reinforce solutions discussed with therapists (Tirel et al., 2020). Online counselling in addition to motivating clients to rapidly seek support sooner than later, it allows counselees to talk freely and more in details about their problems in comparison with face-to-face counselling (Situmorang, 2020). Online counselling in addition to reducing the transportation cost and hassle, it can be held anywhere and interestingly, it is regarded as a great platform by young clienteles as they can freely express the problems that they are encountering without shame (Mansyur et al., 2019). Web-based intervention has become so popular and trusted by the young persons they now do not feel ashamed to discuss sensitive issues such mental health that are impacting their lives which they would not have talk about with counselor in traditional face-to-face counselling sessions (Li \& Leung, 2020).

\section{Confidentiality and privacy}

Confidentiality and privacy are core values of all civil societies and relationships including professional ones (BASW, 2021). With assured and protected confidentiality and privacy, people are at liberty to openly discuss their opinion being positive or negative and in the same vein, share things that are deeply rooted in their hearts (Derlega \& Chaikin, 1977). At certain stage in life for most people, their health status is private and any opportunity that would assure them such while receiving appropriate and timely treatment would not only be a guarantor but a therapy and clienteles magnetizer by itself as corroborated by e-counselling in addition to expediting referral, it is favored by students because of its flexibility, confidentiality, and easy access (Supriyanto et al., 2020). Young persons are attracted to e-counselling because of privacy and lack of emotional exposure (King et al., 2006).

Similarly, online counselling is useful to the counsellors because it ensures confidentiality and provides emotional and physical safety for them since the clients emotional proximity is significantly reduced (Bambling et al., 2008). The platforms for e-counselling are rapidly increasing in addition to instant messaging, videoconferencing, video chat, e-mails and so too, is the degree of security as clients are more willing to share confidential information (Li \& Leung, 2020).

\section{Efficiency and effectiveness improvement}

Today, the world seems to be inundated with different pandemics that are not only posing heaven burden on overstretched services but as well significantly battering quality, efficiency and effectiveness for numerous reasons (Senbeta Deriba et al., 2020). Ensuring efficiency and effectiveness is the cornerstone of all service providers especially to those for battling with poor health and difficult circumstances. Thus, any intervention strategy that is cost effective and convenient to adopt will be widely cherished by both service providers and beneficiaries as articulated: cyber psychological intervention has the capacity to increase care delivery and its effectiveness up to fourfold especially during pandemic (Alavi et al., 2020). Cyber counselling has been acclaimed as more effective method of rendering counselling services during the Covid-19 pandemic (Situmorang, 2020). Cyber interventions has proved to be effective in supporting the working population especially those who are the first time support seekers to address their problems (Giroux et al., 2017). 
Similarly, when online consultation and guidance is provided, self-help support for problematic alcohol consumption can be more effectively minimized within a 10-week period (Sundström et al., 2016). Online counselling in Japan has among other things reduced suicidal thinking, emotional distress and social withdrawal among medical students in particular (Li \& Leung, 2020). Online counselling is critical for university students in two major respects, chiefly, for re-engineering the needed support processes and easy access to information for guidance (Amritesh \& Chatterjee, 2014). Although e-support is not yet well understood and adopted by many professionals, since the world is moving virtual; the knowledge should be a motivating factor rather a de-motivating one, bearing in mind the need to respond to the needs of clienteles which the medium can deliver with greater efficiency and effectiveness (Hanley, 2006). Despite the fact that there is a scarcity of quantitative data, e-therapy is greatly promising to be effective and revolutionizing psychological and behavioral changes (Barak et al., 2009).

In the same vein, web-counselling is advantageous because it improves the efficiency of counselling, increases the rate of delivery with greater efficiency with less repetition especially in group counselling, increases flexibility and independence and furthermore, breaks the barriers of time, distance, and space as it can be conduct despite where the client is located and even outside the normal working time frame (Paterson et al., 2019). The effectiveness of web-counselling is almost the same like that of the traditional face-to-face counselling which is a compelling evidence that online counselling is paying some dividend (Terry, 2009). Web-counselling is promising exponentially and has registered great successes and efficiency both in terms of outcomes and building strong alliance among online clienteles (Terry, 2009). Web-therapy has been found to be efficient in treating a number of psychological problems including panic disorder, tinnitus disorder, depression, posttraumatic stress disorder, and body image concerns (Abbott et al., 2008).

Additionally, e-therapy has been found to one of the most effective and efficient methods of treating a multiple of psychological problems (Abbott et al., 2008). E-therapy is on the average as effective or almost as effective as face-to-face therapy as quoted in Barak et al. 2008:30 (Gainsbury \& Blaszczynski, 2011). E-therapy is commendable for yielding positive behavioral change more especially those engage in drug abuse and those who are drug addicts (Gainsbury \& Blaszczynski, 2011). However, (Holmes \& Kozlowski, 2015) found something seemingly contrary: in view of the physical presence of the counsellor, cohesiveness, safety, and the method of service delivery, participants opined that face-to-face counselling as a group is better and more effective.

\section{All time access to multiple therapists, resources with no transport cost and hassle}

To access quality and relevant services is one of the fundamental contracts that citizens and their respective governments have entered into (Bërdufi \& Dushi, 2015). In some instances, it is critical to have the opportunity to access different services providers and resources in order to choose the most appropriate, affordable and those with no associated cost especially in having to move around in a highly mobility constrained communities (Beladi, 2017). Thus, any strategy to access health services that allows easy access to multiple service providers, resources at all times with a click on the keyboard, with reduced movement and associated cost while improving technological knowhow; a fundamental requisite for survival in the modern world (NAS, 2021), will be the first choice of many service seekers concurring with web-counselling is beneficial to communities in many ways such as being available most of the time, reasonably cheaper, it makes record keeping and access easier; and has the great potential to reach wider population including those who would not have sought face-to-face counselling (Situmorang, 2020). In comparison with face-to-face interventions, the attrition rate in e-therapy is far more lower which could be attributed to many factors such the all-time availability of graphics, pictures, video, and audio files to strengthen applied techniques (Abbott et al., 2008). Internet counselling permits counselees to tap the expertize and experiences of people far away from their homeland, environment or country (Situmorang, 2020).

Similarly, e-counselling is advantageous in many regards such as being available throughout, saving clienteles from the trouble of traveling, cost of counselling, reduces problems associated with shortages of specialists (Tirel et al., 2020). Cyber counselling is rewarding for among other things, it decreases the need to travel long distance, it provides the sought anonymity, security, privacy; and furthermore, it reduces the negative feelings for a client having to visit a counsellors even the pastoral ones (Situmorang, 2020). With online interventions in mental health services, it does not only provide quick responses to emergency situations, but equally improve the effectiveness and quality of emergency interventions through improved knowhow in the application of new technology (Liu et al., 2020). Beneficiaries of e-therapy commented that it is satisfactory, pleasant, full of client-worker relationship; and did not miss face-to-face counselling (Sucala et al., 2012).

\section{Client-driven therapy sessions}

In any partnership, the unhindered right for the active participation of all partners is fundamental. The importance of this principle cannot be overemphasis since each partner possesses some unique skills and 
knowledge relevant to the attainment of the fundamental objectives of the venture (McQuaid, 2000). In business there is an old adage which claims that clients are always right which is seemingly equivalent to the self-determination principle in social work. In essence, in democratic societies, beneficiaries should be at the driving seat in determining the quality, quantity, accessibility of essential social services particularly healthcare services. In some instance, it is not uncommon that clients are not consulted by professionals in treatment planning resulting in not only poor adherence but unnecessary long treatment and failures (Walters-Salas, 2012). Thus, any method of services delivery which is client-driven does only pay greater dividend but commands the respect of most as justified in cyber counselling to a large degree, counselees are in control of the sessions as they can freely hang up, log off, login and even move away from the camera, etc. without any negative repercussion (Situmorang, 2020). The advantages of web-counselling include but not restricted to access increment, convenience, clients ability to determine when to reply to issues under discussion, allows clients to compose and type messages, and furthermore, records are permanently available and accessible at no cost or at reasonable cost, enjoying writing as a therapeutic, anonymity, client autonomy and empowerment, and above all, it is being regarded as a novel technique (Shiller, 2009).

\section{Challenges}

Loss of human factor and complete virtual relationship

In any contractual relationship, it is fundamental parties can feel the presence of the other especially by seeing him or her physically. If that is impossible, touching would be a remarkable option. This is critical because it goes a long way in building and consolidating that highly needed bondage even in a client-worker relationship or in a mere working relationship. It enhances understanding each other, being empathetic and the urges to deliver to the best of one's ability to advert disappointment and guilt (Khattar, 2014). However, in a complete virtual relationship sometimes, it is with difficulties that one feels the presence of other and leave alone adequately understanding what $\mathrm{s} /$ he is grappling with and as well be literally part of it while never carried away as a professional as encapsulated: although e-counselling is suitable for all types of counselling, therapists must be extremely careful during group counselling as invisibility can make it complicated and less effective (Barak et al., 2009). Online counselling for a number of reasons such as the physical distance between the counsellor and counselee and inability for parties to be connected psychologically and emotionally has violated some fundamental principle of the therapeutic relationships (Terry, 2009). In spite of the fact that cyber counselling involves the use of gargets such as computers and the internet, still it has the same capacity like the traditional face-to-face counselling in building strong alliance between counsellor and counselee (Terry, 2009). Though web-based intervention is completely virtual, in e-counselling, both the social worker and counselee go through very much similar experiences to those that are common in a face-to-face counselling session or even higher therapeutic alliance (Barak et al., 2009). In spite of e-therapy heavy reliance on textual relationship, research has confirmed that close, empathic, warm, and allied therapeutic relationship can be formed and sustain for the needed substantial impacts on the life of the clienteles (Barak et al., 2009).

\section{Internet connectivity}

In the $21^{\text {st }}$ century, the internet has nearly become an integral part of the world order in the sense that majority of the activities of all types are executed via it. Online transactions are becoming indispensable especially with the advent of the Covid-19 pandemic (Sornaganesh, 2020). Therefore, any nation or institution that cannot ensure uninterrupted connectivity in executing its cardinal responsibilities including the health sector it is bound to create huge problems in people accessing their services resulting in plethora of frustrations and challenges as encapsulated in cyber counselling is challenged by several factors like lack of strong internet connectivity, nonverbal communication cues, some counselees inability to write clear and concise text messages, the possibilities of misunderstanding and misconception, anxiety for the client and worker especially when there is a delay in communication, verification of clients, uninterrupted security and privacy; and total virtual relationship (Tirel et al., 2020). Online counselling though beneficial, is handicapped by inadequate internet access, web-chat communication, counselors' focus on referral, and limitations in addressing the greater concerns of families (Dilkes-Frayne et al., 2019). Web-therapy can sometimes be constrained by many factors namely, lack of time and place, invisibility, reliance on textual relationship, lack of non-verbal cues, lack of adequate and straightforward words to express feelings, and internet failures (Barak et al., 2009). In spite of the positive impacts of e-therapy, there are some great concerns that are associated with it for example, internet connectivity, legal and ethical issues, cost and sometimes it constant availability (Gainsbury \& Blaszczynski, 2011).

\section{Less non-verbal and verbal cues}

Seemingly, in all relationships including the professional ones understanding each other and feeling almost the same most of the time if not all the time is fundamental (Ha \& Longnecker, 2010). To attain this, effective communication, through any appropriate and affordable mean is indispensable. Most people, especially those in poor health or difficult circumstances, to make a point, feel well understood and understand others especially professionals with their gamut of terminologies, prefer verbal communication complimented by the 
non-verbal ones (Jahan \& Siddiqui, 2019). This is not to say written communication is not effective but circumstances and the rationale for communication are significant determinants of the communication methods. Thus, professionals, not being avail the opportunity to verbally and non-verbally communicate with their clienteles has the potential to negatively impact their effectiveness and efficiency in the delivery of urgently needed services as authenticated: in e-counselling, inability of counsellors to watch the body language of their clienteles has in some instances, result in some degree of misunderstanding between counselees and counsellors (Situmorang, 2020). The lack of non-verbal and verbal cues for some counsellors could result in impoverished and less alive working alliance among other things (Wright, 2002). The effectiveness of webcounselling is seriously constrained due to the absence of non-verbal cue which does not only affect communication, establishment and strengthening of the client-counsellor relationship, determination of the degree of the serious of the problem being encountered by the client including emotional issues but it equally result in misunderstanding in some cases (Chardon et al., 2011).

\section{Misinterpretation and misunderstanding}

In most communication, there are possibilities of misunderstanding if necessary actions are not taken to counter such before the commencement. Misunderstanding can be as a result of many factors including the mode of communication, choice of words and time, poor communication, lack of proper understanding of the audiences and their environment, the competence of the communicator including his or her command of the language plus the non-verbal ones (Sayer, 2013). In a situation, where a communicator doesn't have or have limited information about his or recipients and cannot physically see and feel them as in a complete virtual relationship misinterpretation and misunderstanding can't be a rare occurrence as affirmed by because the medium of communication during online counselling is mostly via text messages doing away with the verbal and non-verbal communication, it may sometimes result in miscommunication or misconceptions between therapist and the counselee (Frye-cox et al., 2020). The absence of non-verbal cues can result in both poor communication, misunderstanding, and difficulties in accurately assessing clienteles problems (Bambling et al., 2008). Due to the absence of verbal and non-verbal cues, there are sometimes series of misunderstanding and as some counsellors seem to spend more time on building rapport with their clienteles instead of focusing more on accomplishing the task (Chardon et al., 2011). In cyber counselling, the exchanging of adequate and concise information between clienteles and counsellors is highly limited which could result in counsellors not properly understanding the problem a client is confronted with negating the formulation of realistic goals and action plan (Chardon et al., 2011).

\section{Limited access to computers and computing skills}

The computers like most modern technological inventions have taken central stage in the life and living conditions of many people especially those in developed and some developing countries. Today, computers and computer skills are needed from placing a simple call to national and international security. Apparently, in the service industries and even some critical social services outlets including education, health, information, etc. are computerized, to access such services computer and its operation skills is near indispensable (Haythornthwaite, 2001). Therefore, any lack of such, create lot of problems for people including professionals in easily and comfortably delivering and clienteles accessing such services as affirmed: the effectiveness of online counselling rests on many factors such as client characteristics, education level, technological literacy, social stigma level of mitigation, geographical location; and proper management of daily schedules (Frye-cox et al., 2020). Web-counselling becomes more effective and efficient if there is sufficient preparation, mechanical information, reasonable access to computers; and adequate support to the unlettered clienteles and potential ones (Situmorang, 2020).

In view of the nature of communication in e-counselling, it is apparent that not all types of clients are fit for such service delivery method so being the case, therapists must make sure that a client fits well vis-à-vis the required technological competence, writing skills, lack of extreme pathology; and the type of concern expressed (Barak et al., 2009). The disadvantages of online counselling include loss of the human factor, lack of non-verbal cues, misinterpretation of words, limited access especially for those without computers and those who are not literate, it is time consuming especially when working with clients who are slow in composing messages, occasional technological failure, security of messages, purchasing extra equipment especially for videoconferencing (Shiller, 2009). In light of access to computers, availability of internet and sometimes the level of literacy, online counselling will not only widen the gap between the poor and rich in terms of accessing it but it has nearly become a service for the privileged (Wright, 2002).

\section{Technological complications and failures}

The modern technological inventions though they are an integral part of our life, they are advancing at unprecedented rate. With such rates, they are not only becoming expensive but equally sophisticated in nature and application. Because of this sophistication, some are not only becoming less user-friendly and difficult to maintain, at worse, they quickly damaged beyond repairs (Carr, 1992). Thus, it is not uncommon for people and institutions to be partially or completely grounded because of technological failure particularly in the third 
world countries (Boyd \& Schweber, 2018). Hence, access to services are gradually becoming remote, sometimes people experienced delay or no access due to some complication or technological failures concurring with internet counselling is not without problems and they include technological failure, logistical issues in terms of counsellors to be on duty, knowing which technology works best for a particular client, familiarization with online services, digital divide, and time differences (Mallen, Vogel, Rochlen, et al., 2005). Additionally, etherapy requires both clienteles and counsellors to be conversant with the internet and above all, being extremely careful with portal, emails and avoid wrongly sending messages to wrong persons (Abbott et al., 2008). To some extent, e-counselling can be challenging for some clienteles due to lack of time, technological complications, being exposed to additional stigma such as being afraid because of the feeling of wasting counsellor time especially if one is slow in thinking and composing messages, feeling shame to login; and difficulties in writing short and concise messages (Hanley \& Wyatt, 2020).

\section{Security and confidentiality}

Security, for many reasons is gradually becoming a rare commodity in some parts of the globe and is a strong concern for most. The scenario is more or less the same both at physical and cyber level (Saier \& Trevors, 2010). Security whether at international, national or personal level is a cardinal factor in the societal socioeconomic and political development (Ebeh, 1970). Seemingly without security, everything is highly at risk of disintegrating vis-à-vis today's complex and numerous threats. Therefore, it is critical that security and confidentiality is ensured in any human development activities including looking for and being engaged in medical treatments otherwise the negative consequences both on the infrastructures and patients can be alarming concurring with for e-therapy to be effective and secure there is a need to fill the legal and social gaps such as legal and policy guidelines for licensure, record keeping, reimbursement, and self-help product initiatives (Maheu et al., 2012). Web-based interventions have great potentials in addressing the therapeutic needs of clients nonetheless, there is greater needs for it regulation and the practice methods applied by professionals (Hanley, 2006). Because online therapy is like any other communication in the internet, there is a high tendency that professionals and clients may be exploited and as such more work and security is needed both in the way professionals communicate, work with their clients to avoid abuse and the enactment of stricter laws and guidelines (Barak et al., 2009). E-counselling while it requires intensive training for counsellors, people have started experiencing some problems because of internet exposure especially the younger generations (Paterson et al., 2019). E-therapy unlike other interventions is not highly regulated and as such exposing both clienteles and therapists to some degree of danger requiring greater attention and care in the process of service delivery (Abbott et al., 2008).

In addition to the problem of scope, cyber therapists are confronted with the problems of confidentiality, record keeping, use of clients' information, marketing not only to ensure wider public acceptance but what type of therapy is best suited for a particular problem, computer-mediated communication competence, trainers and supervisors, cultural competence, wider access and affordability, cost and the right skills (Mallen, Vogel, \& Rochlen, 2005). Others challenges in web-based therapy include it is sometimes mentally demanding to compose and type messages that best explain one's condition especially when under stress, confidentiality threats, jurisdiction issues particularly when something goes wronged, cultural differences, clients knowing when therapists will be available to attend them (Shiller, 2009). However, for e-counselling to be widely appreciated among other things, it calls for ensuring that the information about the services on offer are clearly stated and transparent and the platform is secured to advert being hawked (Hanley \& Wyatt, 2020).

\section{Composing concise and simple messages}

In absolute terms, access and be able to apply modern technology especially that of information, communication and technology is a necessity particularly in developed countries. To effectively and efficiently benefit from the pool of opportunities for growth on offer with safety, it is critical one possesses basic computing literacy for at least, one must be able to type simple message at reasonable speedy (Mohamad Said et al., 2015). Therefore, without such basic knowledge, it will be extremely difficult to maximally utilize and benefit from the revolutionary and transformative power of the information, communication and technology sector even in accessing healthcare services as affirmed: online counselling is demanding and exhausting especially when it comes to reading and understanding complex text messages in order to act appropriately and without delay (Wright, 2002). The potential problems in web-counselling include counsellors' lack of ability to concisely communicate through text messages while avoiding misunderstandings (Mansyur et al., 2019). The effectiveness of web-counselling is significantly challenged because of the time it takes to compose, type and send messages (Chardon et al., 2011).

Similarly, web-counselling in some instances is found to be less effective due to lack of time and some clienteles inability to adequately express themselves through text messages (Chardon et al., 2011). Cyber counselling in addition to answering to inquiries as quickly as possible, it requires recording responses in diaries and clienteles adequate knowledge of computer plus typing short and precise messages to advert misunderstanding (Abbott et al., 2008). The client-worker relationship in e-counselling is not constructed 
through the physical presence of parties and spoken words in most cases, but rather by entering the counselee's mental construct through the written world (Wright, 2002).

\section{Therapists' competence verification, culture, and time differences}

It is fundamental in any relationship particularly contractual one including business; one is familiar with his or her counterpart including his or her level of competence, desires and aspiration (Najat, 2017). This is more compelling in a patient-specialist relationship. It is, because lot of things is expected to be shared including confidential information and above all, it could entail entrusting someone with one's entire health and psychological wellbeing (Birkhauer et al, 2017) as cited in (Johnson, 2019). So too is, to be familiar with his or her culture and the time zone if not in the same geographical location. With such one will be able to make a rational choice, establish contact, build relationship, trust; and work in harmony with minimum constraints. Thus, in the absence of such, particularly in a virtual relationship, it is bound to be challenging as authenticated by cyber counselling though advantageous, it is constrained by the absence of verbal and non-verbal cues, difficulties in ensuring security, confidentiality, standard effectiveness, technological availability, therapist credibility; and strict adherence to ethical values (Muraina et al., 2020). Additionally in cyber counselling, clients being able to determine the competence of therapists, how therapists can exercise the duty to warn and protect client from danger, difficulties in obtaining clienteles' informed consent, client identification, therapists' credentials verification are some serious challenges (Shiller, 2009). In some communities, online counselling is structured in such a way that it is not adequately accessible to the broader society because it is not standalone service, it is meant for people who preferred text communication and out of working hours consultations, and relatively it focuses more on giving information, brief intervention, referral, and above all, it is not culturally and linguistically diverse to ensure multiple languages and culturally sensitive and appropriate services availability (Dilkes-Frayne et al., 2019).

\section{Client identification}

For any service provider, to effectively and efficiently meet the needs and the aspiration of his or her customers, it is absolute that s/he knows who they are, what they exactly want, their culture and even their geographical location because all these factors among others can sometimes influence customers' satisfaction, the nature of the products and methods of delivery (Camilleri, 2018). In the same vein, for medical or psychosocial practitioners to effectively work and support their patients to restore their health, it is fundamental the identity and health condition of the clientele is well established (Zolnierek, 2011). Most importantly, patients are partners in the treatment planning and its execution (Pomey et al., 2015). In the absence of such, the treatment is likely to suffer as it is sometime the case in complete virtual relationship concurring with web-counselling though advantageous in many aspects, its limitations include not knowing the physical conditions of the clients, their culture and norms which may not only result in the application of inappropriate approaches but worse of all, it can lead to a counsellor misinterpretation of client's feelings, thoughts, and behaviors (Chester \& Glass, 2006). E-counselling is not without constrains and limitations which include sometimes lack of visual and auditory communication equipment, inability to ascertain the clientele's identity, security of online shared information, and acquiring competent therapists who can conveniently apply these modern and relatively new technologies (Abbott et al., 2008).

\section{Delay in rapid and emergency support delivery}

One of the greatest satisfactions a service provider can derive from a contractual relationship is putting a smile on a customer's face because of satisfaction when it was needed most. Therefore, the capacity to rapidly deliver services especially in emergency situations is cardinal in any service outlet being private or public (Amro et al., 2018). In the absence such, especially in the healthcare services, clients' tensions don't only surge but practitioners and citizens feel disappointed as substantiated by some of the ethical and legal considerations in web-counselling include client's safety, privacy, inability to deliver immediate services especially during crises, and jurisdiction matters as there are no clear laws in most instances that regular it vis-à-vis who clinicians can and cannot offer help (Frye-cox et al., 2020). To effectively address the mental health needs of young persons in the developed countries time factor must be addressed during online counselling (King et al., 2006). Due to the slowness of some clients in composing their text messages or a prolong pause in clients reacting to messages to expedite the process, it deters counsellors' ability to intervene effectively and efficiency either because of running out of time or energy or both, and above all, it can sometimes make counsellor feel guilty for not being able to adequately engage with their clients (Bambling et al., 2008).

\section{Impersonation and giving false information}

With the unprecedented increase in insecurity both physically and psychologically due to numerous factors, it is not uncommon for one to commence even a serious business with a party under a false identity. Sometime people do not want to give their correct identify which can be attributed either to human nature or series of serious disappointments meted on people. Thus, it seems people are not living in a secured world especially when it comes to personal data and its associates (Greenhalgh et al., 2016). Working with false information or person with a false identity can be disappointing especially as a healthcare or social work 
practitioner (Ofcom, 2021). Nonetheless, it is equally demanding to login into a computer and start sharing personal and confidential information with a person whom have never known (Rafique, 2017). Thus, impersonation and giving false information in spite of its negative impacts, is not new in the start of complete virtual relationship as substantiated: e-counselling because of its nature, it is besets by a number of constraints such as impersonation, identity concealment, emergency service delivery difficulties, complete reliance on technology, the digital divide, difficulty in communicating effectively across different culture, collection of service fee, adherence to professional standard, privacy and so forth (Barak et al., 2009). With e-counselling, the danger of clienteles giving incorrect and misleading information is far more greater in comparison to faceto-face counselling (Abbott et al., 2008).

\section{Staff re-training, hiring of new ones and purchasing new equipment,}

To be on top of latest technological inventions is gratifying in many respects bearing in mind today most activities are conducted online especially with the advent of Covid-19 pandemic (UN, 2020) \& (Mishna et al., 2020). Therefore, to survive in the service sector whether in the private or public; recruiting and maintaining experts or at the minimum highly literate staff in information communication technology is a must. It is equally significant to conduct some in-service training for staff to catch up with recent innovations (Mwantimwa, 2019). Thus, the general public including practitioners' needs fairly solid command of information communication technology (ICT) otherwise customers or clienteles access to services and the capacity for providers to render them with minimum limitations can be a challenged as corroborated: to ensure the general public and practitioners use teletherapy, various local and central governments need to conduct sensitization and educational campaigns and allocate funds for training in computer education (Rodda et al., 2013). For clinicians and practitioners to apply web-based interventions they need to be trained to be familiar with the technology and the associated techniques (Boldrini et al., 2020). In light of the significance of web-therapy during pandemics, it is recommended that trainers include telepsychotherapy in their training modules, encourage patients to use the web at home, practitioners to use videoconferencing to deliver remote therapy; and furthermore, motivate clinicians and the general public to subscribe to telepsychotherapy (Boldrini et al., 2020).

Similarly, online interventions have significantly stretched counsellors, trainers, and educators to design programs that require greater focus on technology to be able to conveniently apply video teleconferencing, smart mobile devices, cloud computing, virtual worlds, virtual reality; and electronic games (Maheu et al., 2012). The need for training web-therapists can be both financially and intellectual demanding as they need adequate preparation in both how to apply the theoretical knowledge and practical application of computers programmes and text messages without offending and boring clienteles (Abbott et al., 2008).

Additionally, because of remoteness, cyber therapy requires extra efforts to engage clienteles in ensuring they complete their treatment which sometimes can be challenging (Abbott et al., 2008). Due to lack of technical knowhow and increase associated costs, most health practitioners find it extremely difficult to embraced and apply web-based therapeutic software (Barak et al., 2009). In spite of all these, traditional faceto-face counselling can be demanding in some cases because of having to create a space for it in somehow a busy life, it is technologically challenging and above all, it goes with some continuous mental stigma for openly seeking help (Hanley \& Wyatt, 2020).

\section{Conclusion}

In conclusion, while the potentials include accessibility, affordability, improved efficiency and effectiveness, freedom of expression, round the clock access to therapists and reference materials, global access to experts at moderate cost, confidentiality, etc. the challenges include making the services accessible and affordable to unlettered and financial disadvantaged clienteles, re-training of staff, improving security and availability of internet, regular upgrading of IT infrastructures, etc.

\section{Acknowledgement}

I sincerely acknowledge the technical assistance and support of my Gambian colleagues and our Information and Technology Department in writing this manuscript.

\section{References}

Abbott, J. A. M., Klein, B., \& Ciechomski, L. (2008). Best practices in online therapy. Journal of Technology in Human Services, 26(2-4), 360-375. https://doi.org/10.1080/15228830802097257

Afshan, A. (2015). Shyness, Self-Construal, Extraversion-Introversion, Neuroticism, and Psychoticism / Enhanced Reader. moz-extension://625161f8-398d-4b7f-9361-9af8c4d26e96/enhancedreader.html?openApp\&pdf=https\%3A\%2F\%2Fjournals.sagepub.com\%2Fdoi\%2Fpdf\%2F10.1177\%2F215824 4015587559 
Alavi, N., Yang, M., Stephenson, C., Nikjoo, N., Malakouti, N., Layzell, G., Jagayat, J., Shirazi, A., Groll, D., Omrani, M., O'Riordan, A., Khalid-Khan, S., Freire, R., Brietzke, E., Gomes, F. A., Milev, R., \& Soares, C. N. (2020). Using the online psychotherapy tool to address mental health problems in the context of the COVID-19 pandemic: Protocol for an electronically delivered cognitive behavioral therapy program. JMIR Research Protocols, 912). https://doi.org/10.2196/24913

Amritesh, S. C. M., \& Chatterjee, J. (2014). Emerging scenario of online counseling services in India: A case of egovernment intervention. Transforming Government: People, Process and Policy, 8(4), 569-596. https://doi.org/10.1108/TG-10-2013-0040

Amro, N., Kamel, A. M. A., Qtait, M., Yagi, H., Amro, B., Amro, R., \& Amro, R. (2018). Factors Affect Patients Satisfaction in Emergency Departments in Palestine. In An International Peer-reviewed Journal(Vol. 54). www.iiste.org

Bambling, M., King, R., Reid, W., \& Wegner, K. (2008). Online counselling: The experience of counsellors providing synchronous single-session counselling to young people. Counselling and Psychotherapy Research, 8(2), 110-116. https://doi.org/10.1080/14733140802055011

Barak, A., Klein, B., \& Proudfoot, J. G. (2009). Defining internet-supported therapeutic interventions. Annals of Behavioral Medicine, 38(1), 4-17. https://doi.org/10.1007/s12160-009-9130-7

BASW. (2021). Privacy Policy. https://www.basw.co.uk/privacy-policy

BBC. (2021). The science behind why some of us are shy - BBC Future. https://www.bbc.com/future/article/20190604-the-science-behind-why-some-of-us-are-shy

Békés, V., \& Doorn, K. A. van. (2020). Psychotherapists' attitudes toward online therapy during the COVID-19 Pandemic. Journal of Psychotherapy Integration, 302), 238-247. https://doi.org/10.1037/int0000214

Beladi, H. (2017). How Transport Costs Affect the Decision to Purchase a New or a Remanufactured Good.

Bërdufi, N., \& Dushi, D. (2015). Social Contract and the Governments Legitimacy. Mediterranean Journal of Social Sciences. https://doi.org/10.5901/mjss.2015.v6n6s1p392

Boldrini, T., Schiano Lomoriello, A., Del Corno, F., Lingiardi, V., \& Salcuni, S. (2020). Psychotherapy During COVID-19: How the Clinical Practice of Italian Psychotherapists Changed During the Pandemic. Frontiers in Psychology, 11(October). https://doi.org/10.3389/fpsyg.2020.591170

Boyd, P., \& Schweber, L. (2018). Unintended consequences: institutional artefacts, closure mechanisms and the performance gap. Building Research and Information, 46(1), 10-22. https://doi.org/10.1080/09613218.2017.1331096

Camilleri, M. A. (2018). Understanding Customer Needs and Wants (pp. 29-50). https://doi.org/10.1007/9783-319-49849-2_2

Carr, H. H. (1992). Factors that affect user-friendliness in interactive computer programs. Information and Management, 22(3), 137-149. https://doi.org/10.1016/0378-7206(92)90067-P

Chardon, L., Bagraith, K. S., \& Robert, J. K. (2011). Counseling activity in single-session online counseling with adolescents: An adherence study. Psychotherapy Research, 21(5), 583-592. https://doi.org/10.1080/10503307.2011.592550

Chebli, J. L., Blaszczynski, A., \& Gainsbury, S. M. (2016). Internet-Based Interventions for Addictive Behaviours: A Systematic Review. Journal of Gambling Studies, 32(4), 1279-1304. https://doi.org/10.1007/s10899016-9599-5

Chester, A., \& Glass, C. A. (2006). Online counselling: A descriptive analysis of therapy services on the Internet. British Journal of Guidance and Counselling, 34(2), 145-160. https://doi.org/10.1080/03069880600583170

Chomba, E., Murray, L., Kautzman, M., Haworth, A., Kasese-Bota, M., Kankasa, C., Mwansa, K., Amaya, M., Thea, D., \& Semrau, K. (2010). Integration of services for victims of child sexual abuse at the university teaching hospital one-stop centre. Journal of Tropical Medicine, 2010. https://doi.org/10.1155/2010/864760

Collier, A. F., \& Wayment, H. A. (2018). Psychological Benefits of the "Maker" or Do-It-Yourself Movement in Young Adults: A Pathway Towards Subjective Well-Being. Journal of Happiness Studies, 19(4), 12171239. https://doi.org/10.1007/s10902-017-9866-X

Cresswell, J., \& Underwood, C. (2004). Location, Location, Location : Implications of Geographic Situation on Australian Student Performance in PISA 2000.

Derlega, V. J., \& Chaikin, A. L. (1977). Privacy and Self-Disclosure in Social Relationships. Journal of Social Issues, 33(3), 102-115. https://doi.org/10.1111/j.1540-4560.1977.tb01885.x

Dilkes-Frayne, E., Savic, M., Carter, A., Kokanović, R., \& Lubman, D. I. (2019). Going Online: The Affordances of Online Counseling for Families Affected by Alcohol and Other Drug Issues. Qualitative Health Research, 29(14), 2010-2022. https://doi.org/10.1177/1049732319838231

Ebeh, J. (1970). National Security and National Development: A Critique. AFRREV IJAH: An International Journal of Arts and Humanities, 4(2), 1-14. https://doi.org/10.4314/ijah.v4i2.1

Ellis, T. E., Schwartz, J. A. J., \& Rufino, K. A. (2018). Negative Reactions of Therapists Working with Suicidal Patients: a CBT/Mindfulness Perspective on "Countertransference." International Journal of Cognitive Therapy, 11(1), 80-99. https://doi.org/10.1007/s41811-018-0005-1 
Frings, D., Hogan, C. J., Jn-Pierre, K. H., Wood, K. V., Holmes, M., \& Albery, I. P. (2020). Online and face-to-face extended brief interventions for harmful alcohol use: client characteristics, attendance and treatment outcomes. Counselling Psychology Quarterly, 33(3), 415-426. https://doi.org/10.1080/09515070.2018.1555516

Frye-cox, N., Neal, C. W. O., \& Wendling, S. B. (2020). Understanding Asynchronous Counseling : A Review of Effectiveness and Implementation Considerations.

Gainsbury, S., \& Blaszczynski, A. (2011). A systematic review of Internet-based therapy for the treatment of addictions. Clinical Psychology Review, 31(3), 490-498. https://doi.org/10.1016/j.cpr.2010.11.007

Giroux, I., Goulet, A., Mercier, J., Jacques, C., \& Bouchard, S. (2017). Online and mobile interventions for problem gambling, alcohol, and drugs: A systematic review. Frontiers in Psychology, 8(JUN). https://doi.org/10.3389/fpsyg.2017.00954

Goldman, J., Salus, M. K., Wolcott, D., \& Kennedy, K. Y. (2003). USER MANUAL SE RIES The Foundation for Practice to Child Abuse and Neglect: The Foundation for Practice with. Office.

Grant, D. D. (2006). Overlooked Victims: Working with Non-Offending Caregivers in Child Sexual Abuse Cases. Alabama Counseling Association Journal, 32(2), 22-27.

Greenhalgh, T., Vijayaraghavan, S., Wherton, J., Shaw, S., Byrne, E., Campbell-Richards, D., Bhattacharya, S., Hanson, P., Ramoutar, S., Gutteridge, C., Hodkinson, I., Collard, A., \& Morris, J. (2016). Virtual online consultations: Advantages and limitations (VOCAL) study. BMJ Open, 6(1), e009388. https://doi.org/10.1136/bmjopen-2015-009388

Ha, J. F., \& Longnecker, N. (2010). Doctor-patient communication: A review. In Ochsner Journal(Vol. 10, Issue 1, pp. 38-43). Ochsner Clinic, L.L.C. and Alton Ochsner Medical Foundation. https://doi.org/10.3329/jbcps.v32i2.26036

Hall, M., \& Hall, J. (2011). The Long-Term Effects of Childhood Sexual Abuse: Counseling Implications. VISTAS Online, 199(2), 1-7. http://counslingoutfitters.com/vistas/vistas11/Article_19.pdf

Hanley, T. (2006). Developing youth-friendly online counselling services in the United Kingdom: A small scale investigation into the views of practitioners. Counselling and Psychotherapy Research, 6(3), 182-185. https://doi.org/10.1080/14733140600857535

Hanley, T., \& Wyatt, C. (2020). A systematic review of higher education students' experiences of engaging with online therapy. Counselling and Psychotherapy Research. https://doi.org/10.1002/capr.12371

Haythornthwaite, C. (2001). Introduction: The Internet in Everyday Life. American Behavioral Scientist, 45(3), 363-382. https://doi.org/10.1177/00027640121957240

Holmes, C. M., \& Kozlowski, K. A. (2015). A Preliminary Comparison of Online and Face-to-Face Process Groups.

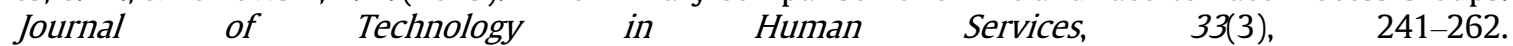
https://doi.org/10.1080/15228835.2015.1038376

Jahan, F., \& Siddiqui, H. (2019). Good Communication between Doctor-Patient Improves Health Outcome. European Journal of Medical and Health Sciences, 1(4). https://doi.org/10.24018/ejmed.2019.1.4.84

Johnson, T. (2019). The Importance of Physician-Patient Relationships Communication and Trust in Health Care - Duke Personalized Health Care. https://dukepersonalizedhealth.org/2019/03/the-importance-ofphysician-patient-relationships-communication-and-trust-in-health-care/

Judd, K. A., \& Vandenberg, B. (2014). Effects of religious stigma and harm on perceived psychopathology. Mental Health, Religion and Culture, 175), 508-519. https://doi.org/10.1080/13674676.2013.856001

Kantor, V., Knefel, M., \& Lueger-Schuster, B. (2017). Perceived barriers and facilitators of mental health service utilization in adult trauma survivors: A systematic review. In Clinical Psychology Review (Vol. 52, pp. 5268). Elsevier Inc. https://doi.org/10.1016/j.cpr.2016.12.001

Khattar, T. (2014). The Role of Empathy in building Counselling Self-Efficacy for Counsellors-in-Training. https://www.researchgate.net/publication/265729478_The_Role_of_Empathy_in_building_Counselling _Self-Efficacy_for_Counsellors-in-Training

King, R., Bambling, M., Lloyd, C., Gomurra, R., Smith, S., Reid, W., \& Wegner, K. (2006). Online counselling: The motives and experiences of young people who choose the Internet instead of face to face or telephone counselling. Counselling and Psychotherapy Research, G(3), 169-174. https://doi.org/10.1080/14733140600848179

Lazuras, L., \& Dokou, A. (2016). Mental health professionals' acceptance of online counseling. Technology in Society, 44, 10-14. https://doi.org/10.1016/j.techsoc.2015.11.002

Li, T. M. H., \& Leung, C. S. Y. (2020). Exploring student mental health and intention to use online counseling in Hong Kong during the COVID-19 pandemic. In Psychiatry and Clinical Neurosciences (Vol. 74, Issue 10, pp. 564-565). Blackwell Publishing. https://doi.org/10.1111/pcn.13117

Liu, S., Yang, L., Zhang, C., Xiang, Y. T., Liu, Z., Hu, S., \& Zhang, B. (2020). Online mental health services in China during the COVID-19 outbreak. In The Lancet Psychiatry (Vol. 7, Issue 4, pp. e17-e18). Elsevier Ltd. https://doi.org/10.1016/S2215-0366(20)30077-8

Maheu, M. M., Pulier, M. L., McMenamin, J. P., \& Posen, L. (2012). Future of telepsychology, telehealth, and various technologies in psychological research and practice. Professional Psychology: Research and 
Practice, 43(6), 613-621. https://doi.org/10.1037/a0029458

Mallen, M. J., Vogel, D. L., \& Rochlen, A. B. (2005). The Practical Aspects of Online Counseling: Ethics, Training, Technology, and Competency. In The Counseling Psychologist (Vol. 33, Issue 6). https://doi.org/10.1177/0011000005278625

Mallen, M. J., Vogel, D. L., Rochlen, A. B., \& Day, S. x. (2005). Online Counseling: Reviewing the Literature From a Counseling Psychology Framework. In The Counseling Psychologist (Vol. 33, Issue 6). https://doi.org/10.1177/0011000005278624

Mansyur, A. I., Badrujaman, A., Imawati, R., Nur, D., Studi, P., Konseling, B., Jakarta, U. N., Studi, P., Dakwah, M., Jakarta, S. H., \& Maret, U. S. (2019). Konseling Online Sebagai Upaya Menangani Masalah. Jurnal Pendidikan IImu Sosial, 29(2), 140-154.

Maté-Sánchez-Val, M., López-Hernandez, F., \& Rodriguez Fuentes, C. C. (2018). Geographical factors and business failure: An empirical study from the Madrid metropolitan area. Economic Modelling, 74, 275 283. https://doi.org/10.1016/j.econmod.2018.05.022

McLeod, S. (2018). Communication rights: Fundamental human rights for all. In International Journal of Speech-Language Pathology (Vol. 20, Issue 1, pp. 3-11). Taylor and Francis Ltd. https://doi.org/10.1080/17549507.2018.1428687

McQuaid, R. (2000). The theory of partnership: Why have partnerships? https://www.researchgate.net/publication/291300642_The_theory_of_partnership_Why_have_partner ships

Mishna, F., Milne, E., Bogo, M., \& Pereira, L. F. (2020). Responding to COVID-19: New Trends in Social Workers' Use of Information and Communication Technology. Clinical Social Work Journal, 1, 3. https://doi.org/10.1007/s10615-020-00780-x

Mohamad Said, M. N. H., Mohd Tahir, L., Ali, M. F., \& Megat Zakaria, M. A. Z. (2015). ICT Literacy and Readiness in Using Computers among Headteachers in their Tertiary Learning Experiences and School Management Tasks. International Journal of Emerging Technologies in Learning (IJET), 102), 63. https://doi.org/10.3991/ijet.v10i2.4405

Muller, L., \& Ruffieux, B. (2011). Do price-tags influence consumers' willingness to pay? On the external validity of using auctions for measuring value. Experimental Economics, 14(2), 181-202. https://doi.org/10.1007/s10683-010-9262-4

Muraina, K. O., G, S. M., \& Kabir, Z. M. (2020). The Future Of Guidance And Counselling In The 21st Century In Nigeria: Changing Face-To-Face Counselling Through Cyberspace Counselling. International Journal on Research in STEM Education, 2(2), 91-98. https://doi.org/10.31098/ijrse.v2i2.197

Muridzo, N., Chikadzi, V., \& Kaseke, E. (2018). Challenges faced by professionals working in child sexual abuse multi-sectorial forums: A case of the victim-friendly system in Zimbabwe. Social Work (South Africa), 54(4), 452-468. https://doi.org/10.15270/54-4-672

Mwantimwa, K. (2019). ICT usage to enhance firms' business processes in Tanzania. Journal of Global Entrepreneurship Research, 91), 46. https://doi.org/10.1186/s40497-019-0170-6

Najat, B. (2017). Importance of Customer Knowledge in Business Organizations. International Journal of Academic Research in Business and Social Sciences, 711). https://doi.org/10.6007/IJARBSS/v7-i11/3449

NAS. (2021). CHAPTER 2 SCIENCE AND TECHNOLOGY IN MODERN SOCIETY / Science, Technology, and the Federal Government: National Goals for a New Era / The National Academies Press. https://www.nap.edu/read/9481/chapter/3

Nations, U. (n.d.). Freedom of Expression, a Fundamental Human Right / United Nations. Retrieved May 6, 2021, from https://www.un.org/en/chronicle/article/freedom-expression-fundamental-human-right

NLASW. (2014). STANDARDS FOR SOCIAL WORK RECORDING.

Ofcom. (2021). Discussion paper: Understanding online false information in the UK / Enhanced Reader. mozextension://625161f8-398d-4b7f-9361-9af8c4d26e96/enhancedreader.html?openApp\&pdf=https\%3A\%2F\%2Fwww.ofcom.org.uk\%2F_data\%2Fassets\%2Fpdf_file\%2F002 7\%2F211986\%2Funderstanding-online-false-information-uk.pdf

Parcesepe, A. M., \& Cabassa, L. J. (2012). Public Stigma of Mental Illness in the United States: A Systematic Literature Review. https://doi.org/10.1007/s10488-012-0430-z

Paterson, S. M., Laajala, T., \& Lehtelä, P. L. (2019). Counsellor students' conceptions of online counselling in Scotland and Finland. British Journal of Guidance and Counselling, 473), 292-303. https://doi.org/10.1080/03069885.2017.1383357

Perle, J. G., Langsam, L. C., \& Nierenberg, B. (2011). Controversy clarified: An updated review of clinical psychology and tele-health. Clinical Psychology Review, 31(8), 1247-1258. https://doi.org/10.1016/j.cpr.2011.08.003

Pomey, M. P., Ghadiri, D. P., Karazivan, P., Fernandez, N., \& Clavel, N. (2015). Patients as partners: A qualitative study of patients' engagement in their health care. PLOS ONE, 10(4). https://doi.org/10.1371/journal.pone.0122499

Rafique, G. M. (2017). Personal Information Sharing Behavior of University Students via Online Social Networks. 
http://digitalcommons.unl.edu/libphilprachttp://digitalcommons.unl.edu/libphilprac/1454

Rodda, S. N., Lubman, D. I., Dowling, N. A., \& McCann, T. V. (2013). Reasons for using web-based counselling among family and friends impacted by problem gambling. Asian Journal of Gambling Issues and Public Health, 3(1), 1-11. https://doi.org/10.1186/2195-3007-3-12

Saier, M. H., \& Trevors, J. T. (2010). Global Security in the 21st Century. https://doi.org/10.1007/s11270-0079522-X

Sayer, I. M. (2013). Misunderstanding and language comprehension. Procedia-Social and Behavioral Sciences, 70, 738-748. https://doi.org/10.1016/j.sbspro.2013.01.118

SCIE. (2019). Social work recording / SCIE. https://www.scie.org.uk/social-work/recording

Senbeta Deriba, B., Abeya Geleta, T., Shukure Beyane, R., Mohammed, A., Tesema, M., \& Jemal, K. (2020). Patient Satisfaction and Associated Factors During COVID-19 Pandemic in North Shoa Health Care Facilities. https://doi.org/10.2147/PPA.S276254

Serdiuk, L., Danyliuk, I., \& Chaika, G. (2018). PERSONAL AUTONOMY AS A KEY FACTOR OF HUMAN SELFDETERMINATION. SOCIAL WELFARE: INTERDISCIPLINARY APPROACH, $\quad 1(8), \quad 85$. https://doi.org/10.21277/sw.v1i8.357

Shiller, I. (2009). Online counselling: A review of the literature. Prepared by: Ilene Shiller, MSW, RSW April 2009. April.

Shonhe, L. (2018). A SERVICE DELIVERY IMPROVEMENT STRATEGY FOR A RECORDS MANAGEMENT PROGRAMME.

https://www.researchgate.net/publication/329058436_A_SERVICE_DELIVERY_IMPROVEMENT_STRATE GY_FOR_A_RECORDS_MANAGEMENT_PROGRAMME

Situmorang, D. D. B. (2020). Online/Cyber Counseling Services in the COVID-19 Outbreak: Are They Really New? The Journal of Pastoral Care \& Counseling: JPCC, 74(3), 166-174. https://doi.org/10.1177/1542305020948170

Sornaganesh, V. (2020). Impact of Covid-19 Outbreak in Digital Payments. https://www.researchgate.net/publication/344546518_Impact_of_Covid19_Outbreak_in_Digital_Payments

Spake, D. F., Beatty, S. E., Brockman, B. K., \& Crutchfield, T. N. (2003). Consumer Comfort in Service Relationships: Measurement and Importance. Journal of Service Research, 5(4), 316-332. https://doi.org/10.1177/1094670503005004004

Spicker, P. (2011). Stigma and social welfare Stigma and social welfare.

Sucala, M., Schnur, J. B., Constantino, M. J., Miller, S. J., Brackman, E. H., \& Montgomery, G. H. (2012). The therapeutic relationship in E-therapy for mental health: A systematic review. Journal of Medical Internet Research, 14(4). https://doi.org/10.2196/jmir.2084

Sundström, C., Gajecki, M., Johansson, M., Blankers, M., Sinadinovic, K., Stenlund-Gens, E., \& Berman, A. H. (2016). Guided and unguided internet-based treatment for problematic alcohol use - A randomized controlled pilot trial. PLOS ONE, 11(7), 1-19. https://doi.org/10.1371/journal.pone.0157817

Supriyanto, A., Hartini, S., Irdasari, W. N., Miftahul, A., Oktapiana, S., \& Mumpuni, S. D. (2020). Teacher professional quality: Counselling services with technology in Pandemic Covid-19. Counsellia: Jurnal Bimbingan Dan Konseling, 102), 176. https://doi.org/10.25273/counsellia.v10i2.7768

Terry, H. (2009). Counselling Psychology and the internet: A review of the quantitative research into online outcomes and within text-based therapy. https://www.researchgate.net/publication/234791042_Counselling_Psychology_and_the_internet_A_re view_of_the_quantitative_research_into_online_outcomes_and_alliances_within_text-based_therapy

Tirel, M., Rozgonjuk, D., Purre, M., \& Elhai, J. D. (2020). When Do People Seek Internet Counseling? Exploring the Temporal Patterns of Initial Submissions to Online Counseling Services. Journal of Technology in Human Services, 38(2), 184-202. https://doi.org/10.1080/15228835.2018.1561348

Tomazic, T., \& Jerkovic, O. S. (2020). Online interventions for the selective prevention of illicit drug use in young drug users: Exploratory study. Journal of Medical Internet Research, 22(4). https://doi.org/10.2196/17688

UN. (2020). Global e-commerce jumps to $\$ 26.7$ trillion, fuelled by COVID-19 / / UN News. https://news.un.org/en/story/2021/05/1091182

UNDESA. (n.d.). Promoting Empowerment of People in achieving poverty eradication, social integration and full employment integration and full employment and decent work for all.

van Kuijk, J., van Driel, L., \& van Eijk, D. (2015). Usability in product development practice; an exploratory case study comparing four markets. Applied Ergonomics, 47, 308-323. https://doi.org/10.1016/j.apergo.2014.10.007

Walters-Salas, T. (2012). The challenge of patient adherence. In Bariatric Nursing and Surgical Patient Care(Vol. 7, Issue 4, p. 186). Dove Press. https://doi.org/10.1089/bar.2012.9960

Whittle, H. C., Hamilton-Giachritsis, C., \& Beech, A. R. (2013). Victims' Voices: The Impact of Online Grooming and Sexual Abuse. Universal Journal of Psychology, 1(2), 59-71. https://doi.org/10.13189/ujp.2013.010206 
Wilson, S. R., Rodda, S., Lubman, D. I., Manning, V., \& Yap, M. B. H. (2017). How online counselling can support partners of individuals with problem alcohol or other drug use. Journal of Substance Abuse Treatment, 78, 56-62. https://doi.org/10.1016/j.jsat.2017.04.009

Wright, J. (2002). Online counselling: Learning from writing therapy. British Journal of Guidance and Counselling, 303), 285-298. https://doi.org/10.1080/030698802100002326

Zolnierek, C. (2011). The importance of knowing the patient. In Issues in Mental Health Nursing(Vol. 32, Issue 6, pp. 392-393). https://doi.org/10.3109/01612840.2011.565543 